УДК 547.537 .9

DOI: 10.33184 /bulletin-bsu-2021.3.20

СИНТЕЗ НОВЫХ ЛИПОФИЛЬНЫХ ПРОИЗВОДНЫХ ФУЛЛЕРЕНА С 60

() И. М. Сахаутдинов ${ }^{1 *}$, А. Ф. Исламова ${ }^{1,2}$, Т. А. Мананов ${ }^{3}$, А. М. Гумеров ${ }^{2,3}$

${ }^{1}$ Уфимский Институт химии УФИЦРАН

Россия, Республика Башкортостан, 450054 г. Уфа, пр. Октября, 69.

${ }^{2}$ Республиканский инженерный лицей-интернат

Россия, Республика Башкортостан, 450032 г. Уфа, ул. Кольцевая, 74.

${ }^{3}$ Уфимский государственный нефтяной технический университет

Россия, Республика Башкортостан, 450064 г. Уфа, ул. Космонавтов 1.

$$
\text { Тел.: + } 7 \text { (347) } 2355560 \text {. }
$$

*Email: ioh039@mail.ru

\begin{abstract}
В данной работе для функиионализации ядра фуллерена Сбо мы использовали реакцию [3+2]-ииклоприсоединения на основе $N$-алкенилзамещеннного ангидрида янтарной кислотьл. Аллены получали реакиией олефинирования кетенов фосфоранами, что в первую очередь связано с мягкими условиями проведения реакиии. Для этого хлорангидириды карбоновых кислот вовлекали в реакиию олефинирования с метил (трифенилфосфоранилиден)аиетатом. Далее по реакиии Morita-Baylis-Hillman [3+2]-ииклоприсоединения алленоатов к фуллереновому каркасу нами впервые синтезированы монофуллерены, содержащие остатки $N$-алкенилзамещеннного ангидрида янтарной кислоты. Полученные конъюгаты фуллерена Сбо показали хорошую растворимость как в органических растворителях, так и в ТВИНЕ-60.
\end{abstract}

Ключевые слова: фуллерены, ангидрид янтарной кислоты, алленоаты, изикопентенофуллерены.

\section{Введение}

Производные фуллерена $\mathrm{C}_{60}$ обладают необычно высокой способностью улавливать свободные радикалы, что может быть использовано при создании антиоксидантов [1-5]. Опыты на животных показывают, что соединения фуллерена заметно повышают их устойчивость к оксидативным стрессам [6]. Основное внимание синтетиков приковано к получению водорастворимых производных фуллерена, тогда как актуальной проблемой современной биохимии является синтез липофильных митохондриально-адресованных антиоксидантов, т.к. митохондрии являются основными источниками активных форм кислорода в клетке [7-10].

\section{Экспериментальная часть}

ИК-спектры записывали на приборе IR-Prestige-21 (Fourier Transform Spectrophotometer Shimadzu) в тонком слое или вазелиновом масле. Спектры ЯМР получены на спектрометре Bruker-AM 500 с рабочей частотой 500.13 МГц $\left({ }^{1} \mathrm{H}\right), 125.76 \mathrm{MГц}$ $\left({ }^{13} \mathrm{C}\right)$, внутренний стандарт - тетраметилсилан (ТМC). Ход реакции контролировали методом тонкослойной хроматографии на пластинках Sorbfil ПТСХ-АФ-А, вещества обнаруживали с помощью паров йода. Температуру плавления определяли на нагревательном столике Boetius. Продукты реакции выделяли с помощью колоночной хроматографии на силикагеле «Chemapol» с размером частиц 40/100 и 100/160 мкм.

\section{Методика получения алленоатов по реакции Виттига}

К суспензии 6.25 ммоль кислоты в 10 мл обезвоженного хлористого метилена добавили пятикратный избыток оксалилхлорида и оставили на ночь. Растворитель и избыток оксалилхлорида упарили на роторном испарителе. Остаток, представляющий собой хлорангидрид, далее использовали без дополнительной очистки. К раствору, полученного при растворении 6.25 ммоль метил (трифенилфосфоранилиден)ацетата в 30мл $\mathrm{CH}_{2} \mathrm{Cl}_{2}$, прикапывали эквимольное количество $\mathrm{Et}_{3} \mathrm{~N}$, раствор охлаждали до $-5{ }^{\circ} \mathrm{C}$. К этому раствору медленно по каплям добавили охлажденный раствор хлорангидрида N-замещенной аминокислоты. Реакционную массу перемешивали в течение 2 ч. Растворитель отогнали, продукт реакции выделили колоночной хроматографией на силикагеле (элюент: петролейный эфир:этилацетат, 4:1).

Метил-4-\{3-[(2E)-додец-2-ен-1-ил]-2,4диоксопирролидин-1-ил бута-2,3-диеноат (2a). Выход 0.41г (35\%). Желтое масло. ИК-спектр (вазелиновое масло), $v / \mathrm{cm}^{-1}: 1229,1462,1680,1738$, 3163. Спектр ЯМР ${ }^{1} \mathrm{H}\left(\mathrm{CDCl}_{3}, \delta\right.$, м.Д., Ј/Гц): 0.81 $(\mathrm{T}, 3 \mathrm{H}), 1.21(\mathrm{M}, 14 \mathrm{H}), 1.9(\mathrm{м}, 2 \mathrm{H}), 1.92\left(\mathrm{м}, 1 \mathrm{H}^{\mathrm{a}}\right), 2.28$ $\left(\mathrm{M}, 1 \mathrm{H}^{\mathrm{b}}\right), 2.42\left(\mathrm{M}, 1 \mathrm{H}^{\mathrm{a}}\right), 2.5\left(\mathrm{M}, 1 \mathrm{H}^{\mathrm{b}}\right), 2.75(\mathrm{M}, 1 \mathrm{H})$, $2.82\left(\mathrm{M}, 1 \mathrm{H}^{\mathrm{b}}\right), 3.63$ (т. $\left.3 \mathrm{H}\right), 5.21(\mathrm{M}, 2 \mathrm{H}), 5.5(\mathrm{M}, 1 \mathrm{H})$, 5.52 (м,1Н), 7.02 (д. 1Н, J 6.0 Гц), Спектр ЯМР ${ }^{13} \mathrm{C}$ : $14.15,22.63,29.08,29.28,29.46,29.51,31.84,32.47$, $33.45,33.86,39.77,52.30,91.69,96.38,123.86,135.8$, $172.88,175.84,178.88,210.10$. 
Метил-5-\{3-[(2E)-додец-2-ен-1-ил]-2,4диоксопирролидин-1-ил\}пента-2,3-диеноат (2b). Выход 0.75г (60\%). Желтое маслообразное веще-

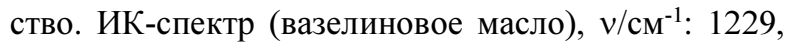
1462, 1680, 1738, 3163. Спектр ЯМР ${ }^{1} \mathrm{H}\left(\mathrm{CDCl}_{3}, \delta\right.$, м.Д., Ј/Гц): 0.81 (т, 3Н), 1.2 (м, 14H), 1.92 (м, 2Н), $2.15\left(\mathrm{M}, 1 \mathrm{H}^{\mathrm{a}}\right), 2.33\left(\mathrm{M}, 1 \mathrm{H}^{\mathrm{b}}\right), 2.64\left(\mathrm{M}, 1 \mathrm{H}^{\mathrm{a}}\right), 2.63\left(\mathrm{M}, 1 \mathrm{H}^{\mathrm{b}}\right)$, $2.70(1 \mathrm{H}), 2.82\left(1 \mathrm{H}^{\mathrm{b}}\right), 3.67$ (т. $\left.3 \mathrm{H}\right), 4.14-4.15$ (м. $\left.2 \mathrm{H}\right)$, $5.48(\mathrm{м}, 1 \mathrm{H}), 5.66(\mathrm{м}, 2 \mathrm{H})$. Спектр ЯМР ${ }^{13} \mathrm{C}$ : 14.05, 22.62, 29.08, 29.27, 29.48, 29.51, 31.83, 32.45, 33.32, $34.00,35.52,39.74,52.11,90.2,90.79,124.07,135.42$, $165.25,175.57,178.48,212.28$

Метил-6-\{3-[(2E)-додец-2-ен-1-ил]-2,4диоксопирролидин-1-ил\}гекса-2,3-диеноат (2c). Выход 0.5 г (52\%). Прозрачное масло. ИК-спектр, v, см$^{-1}:$ 724, 1162, 1263, 1398, 1437, 1698, 1763, 1959. Спектр ЯМР ${ }^{1} \mathrm{H}\left(\mathrm{CDCl}_{3}, \delta\right.$, м.Д., Ј/Гц $: 0.85$ $(\mathrm{T}, 3 \mathrm{H}), 1.23(\mathrm{м}, 14 \mathrm{H}), 1.96(\mathrm{M}, 2 \mathrm{H}), 2.02 \mathrm{м}(2 \mathrm{H}), 2.26$ м $\left(1 \mathrm{H}^{\mathrm{a}}\right), 2.36$ м $\left(1 \mathrm{H}^{\mathrm{b}}\right), 2.72(1 \mathrm{H}), 2.73\left(1 \mathrm{H}^{\mathrm{a}}\right), 2.75$ $\left(1 \mathrm{H}^{\mathrm{b}}\right), 2.91\left(1 \mathrm{H}^{\mathrm{b}}\right), 3.61 \mathrm{м}(2 \mathrm{H}), 3.69 \mathrm{c}(3 \mathrm{H}), 5.22 \mathrm{м}$ $(1 \mathrm{H}), 5.52 \mathrm{м}(1 \mathrm{H}), 5.56 \mathrm{м}(2 \mathrm{H})$. Спектр ЯМР ${ }^{13} \mathrm{C}$ : $14.09,22.66,29.1,29.31,29.33,29.45,29.5,31.87$, $32.52,33.35,33.84,37,42,39.69,51.99,88.37,91.86$, $123.54,135.35,166.07,176.72,179.59,212.65$

Метил-7-\{3-[(2E)-додец-2-ен-1-ил]-2,4диоксопирролидин-1-ил\}гепта-2,3-диеноат (2d) Выход 1.03 г (83\%). Прозрачное масло. ИК-спектр, $v, \mathrm{~cm}^{-1}: 728,1162,1263,1398,1439,1688,1763$, 1975. Спектр ЯМР ${ }^{1} \mathrm{H}\left(\mathrm{CDCl}_{3}, \delta\right.$, м.д., Ј/Гц): 0.82 $(\mathrm{T}, 3 \mathrm{H}), 1.20$ (м, 14H), 1,67 м (2H), $1.95(\mathrm{м}, 2 \mathrm{H}), 2.08$ м $(2 \mathrm{H}), 2.23$ м $\left(1 \mathrm{H}^{\mathrm{a}}\right), 2.32$ м $\left(1 \mathrm{H}^{\mathrm{b}}\right), 2.68\left(1 \mathrm{H}^{\mathrm{a}}\right), 2.70$ $\left(1 \mathrm{H}^{\mathrm{b}}\right), 2.72(1 \mathrm{H}), 2.84\left(1 \mathrm{H}^{\mathrm{b}}\right), 3.49$ т $(2 \mathrm{H}),, 3.67 \mathrm{~T}(3 \mathrm{H})$, 5.19 м (1Н), 5.50 м (1Н), 5.58 м (1Н). Спектр ЯМР ${ }^{13} \mathrm{C}: 14.06,22.62,28.26,29.07,29.26,29.42,29.46$, $29.51,31.84,32.49,33.39,33.85,37,90,39.57,60.32$, 88.66, 94.25, 123.94, 135.54, 166.34, 176.59, 179.43, 212.21 .

\section{Метил-8-\{3-[(2E)-додец-2-ен-1-ил]-2,4-} диоксопирролидин-1-ил\}окта-2,3-диеноат (2e). Выход 0.91 г (87\%). Густое желтое масло. ИКспектр, v, см$^{-1}:$ 726, 1164, 1262, 1397, 1436, 1498, 1767, 1962. Спектр ЯМР ${ }^{1} \mathrm{H}\left(\mathrm{CDCl}_{3}, \delta\right.$, м.д., Ј/Гц): $0.82(\mathrm{~T}, 3 \mathrm{H}), 1.20(\mathrm{M}, 14 \mathrm{H}), 1,58$ м $(2 \mathrm{H}), 1.92(\mathrm{м}, 2 \mathrm{H})$, $1.95(\mathrm{M}, 2 \mathrm{H}), 2.12 \mathrm{м}(2 \mathrm{H}), 2.23 \mathrm{м}\left(1 \mathrm{H}^{\mathrm{a}}\right), 2.28 \mathrm{м}\left(1 \mathrm{H}^{\mathrm{b}}\right)$, $2.66\left(1 \mathrm{H}^{\mathrm{a}}\right), 2.71\left(1 \mathrm{H}^{\mathrm{b}}\right), 2.72(1 \mathrm{H}), 2.82\left(1 \mathrm{H}^{\mathrm{b}}\right), 3.44 \mathrm{~T}$ $(2 \mathrm{H}), 3.67$ с $(3 \mathrm{H}), 5.22$ м $(1 \mathrm{H}), 5.52$ м $(1 \mathrm{H}), 5.54$ м (2Н). Спектр ЯМР ${ }^{13} \mathrm{C}: 14.10,22.57,27.33,28.23$, 29.02, 29.21, 29.37, 29.46, 31.78, 32.43, 33.14, 33.33, $33.83,38,24,39.5,60.24,88.14,94.7,123.9,135.4$, $166.35,176.5,179.36,212.25$

\section{Методика получения цикло- пентенофуллеренов $\mathrm{C}_{60}$}

Фуллерен $\mathrm{C}_{60} 0.14$ ммоль (100 мг) предварительно (за 12 ч) растворили в 35 мл толуола. Алленоаты 0.14 ммоль растворили при комнатной температуре в 5 мл толуола, добавили к фуллерену $\mathrm{C}_{60}$. Затем добавили эквимольное количество $\mathrm{PPh}_{3}$ и кипятили с обратным холодильником на магнитной мешалке в течение 4 ч. $\mathrm{C}$ помощью флэшхроматографии (толуол-петролейный эфир, 4/1) выделили аддукт в индивидуальном виде.

Метил-5-(3-((додец-1-ил)-2,4-диоксопирроли дин-1-ил)этил)- $1^{\prime}$-циклопентено $\quad\left[4^{\prime}, 5^{\prime}: 1,2\right][60]$ фуллерен (3b). Выход 0.071 г (55\%), Спектр ЯМР ${ }^{1} \mathrm{H}\left(\mathrm{CDCl}_{3}, \delta\right.$, м.д., J/Гц): 0.88 (т, 3Н), $1.26($ м, 14H), 2.45 д $\left(1 \mathrm{H}^{\mathrm{a}}\right), 2.56$ д $\left(1 \mathrm{H}^{\mathrm{b}}\right), 2.64$ д $\left(1 \mathrm{H}^{\mathrm{b}}\right), 2.91$ д $\left(1 \mathrm{H}^{\mathrm{a}}\right)$, 3.01 м $(1 \mathrm{H}), 3.94$ с $(3 \mathrm{H}), 4.31$ д $\left(1 \mathrm{H}^{\mathrm{b}}\right), 4.56$ д $\left(1 \mathrm{H}^{\mathrm{a}}\right)$, 5.19 м (2H), 5.37 м (1H), 5.64 м (1H), 7.17 м (1H). Спектр ЯМР ${ }^{13} \mathrm{C}, \delta$, м.д.: 14.16, 22.71, 29.2, 29.37, 29.54, 29.62, 31.92, 32.62, 33.37, 33.88, 34.07, 39.82, $42.52,52.32,55.05,72.27,118.96,123.01,123.63$, $123.82,125.31,128.23,128.46,129.04,132.32,134.34$, $135.00,135.60,135.64,136.15,136.22,136.64$, $136.95,139.36,139.41,139.72,140.41,141.62$, $141.71,141.92,141.95,142.03,142.23,142.46$, $142.68,142.72,142.78,143.10,143.14,144.32,144.46$, $144.57,144.74,144.86,145.20,145.35,145.44$, $145.54, \quad 145.62,145.79, \quad 145.91,145.98,146.01$, $146.05,146.16,146.26,146.28,146.33,146.38$, $146.48,147.28,147.41,148.08,150.43,150.48,150.71$, $156.10,163.79,176.43,179.30$.

\section{Метил-6-(3-((додец-1-ил)-2,4-}

диоксопирролидин-1-ил)пропил) -1' циклопентено[4,5:1f,2f][60]фуллерен (3c).

Выход 0.056 г (40\%). Спектр ЯМР ${ }^{1} \mathrm{H}\left(\mathrm{CDCl}_{3}, \delta\right.$, м.Д., Ј/Гц): 0.86 (т, 3Н), 1.24 (м, 14H), 2.32 д $\left(1 \mathrm{H}^{\mathrm{a}}\right)$, 2.44 м $(2 \mathrm{H}), 2.56$ д $\left(1 \mathrm{H}^{\mathrm{b}}\right), 2.72$ д $\left(1 \mathrm{H}^{\mathrm{b}}\right), 2.91$ д $\left(1 \mathrm{H}^{\mathrm{a}}\right)$, 2.94 м (1H), 3.94 с $(3 \mathrm{H}), 4.15$ д $\left(1 \mathrm{H}^{\mathrm{b}}\right), 4.68$ д $\left(1 \mathrm{H}^{\mathrm{a}}\right)$, 5.23 м (2H), 5.28 м (1H), 5.59 м (1H), 7.26 м (1H). Спектр ЯМР ${ }^{13} \mathrm{C}, \delta$, м.д.: $14.16,22.69,29.18,29.39$, 29.53, 29.61, 31.89, 32.61, 33.37, 33.87, 33.6, 37.42, $37.45,39.75,52.27,55.17,73.89,123.55,123.74$, $124.27,134.19,135.38,135.61,135.64,136.00$, $136.21, \quad 136.34,139.27,139.39,139.81,140.22$, $141.58, \quad 141.65,141.92,142.02,142.20,142.25$, $142.44, \quad 142.63, \quad 142.69, \quad 142.73,143.07, \quad 143.11$, $144.39,144.43,144.48,144.51,145.15,145.30,145.36$, $145.50,145.59,145.90,145.95,146.00,146.12$, $146.22, \quad 146.25,146.30,146.35,146.41,147.26$, $147.39, \quad 148.06,150.46,150.77,152.04,156.45$, $163.98,176.74,179.56$.

Метил-7-(3-((додец-1-ил)-2,4-

диоксопирролидин-1-ил)бутил)-1' циклопентено[4',5':1f,2f][60]фуллерен (3d).

Выход 0.1 г (70\%). Спектр ЯМР ${ }^{1} \mathrm{H}\left(\mathrm{CDCl}_{3}, \delta\right.$, м.д., $\mathrm{J} / Г ц): 0.87(\mathrm{~T}, 3 \mathrm{H}), 1.25$ (м, 14H), 2.01 м (2H), 2.19 м $(2 \mathrm{H}), 2.21$ м (2H), 2.50 м $(2 \mathrm{H}), 2.88$ м $(1 \mathrm{H}), 3.93$ с $(3 \mathrm{H}), 4.79$ м (2H), 5.26 м $(2 \mathrm{H}),$,5.29 м (1H), 5.56 м $(1 \mathrm{H}), 7.26$ м (1Н). Спектр ЯМР ${ }^{13} \mathrm{C}, \delta$, м.д.: 14.12, 22.65, 27.46, 29.12, 29.32, 29.47, 29.55, 31.86, 32.55, $33.34,33.88,34.05,38.29,38.36,39.7,52.14,56.9$, $74.15,123.20,123.98,124.02,128.17,134.03,135.59$, $135.65, \quad 135.92, \quad 136.06, \quad 139.20,139.32,139.67$, $140.16,141.53,141.60,141.83,141.87,141.91$, $142.07,142.16,142.20,142.39,142.58,142.63$, $142.68,143.04,143.08,144.15,144.35,144.42,144.47$, $144.68,144.73,145.02,145.08,145.19,145.30$, 
$145.34, \quad 145.43, \quad 145.53, \quad 145.85, \quad 145.93, \quad 146.07$, $146.16,146.18,146.24,146.30,146.34,147.21$, $147.32,148.06,150.55,150.89,152.39,156.77$, 163.94, 176.52, 179.39.

Метил-8-(3-((додец-1-ил)-2,4-

диоксопирролидин-1-ил)пентил)-1' циклопентено[4',5':1f,2f][60]фуллерен (3e).

Выход 0.136г (80\%). Спектр ЯМР ${ }^{1} \mathrm{H}\left(\mathrm{CDCl}_{3}, \delta\right.$, м.Д., Ј/Гц): 0.86 (т, 3Н), 1.24 (м, 14H), 1.94 (м, 2Н), 2.14 м $(2 \mathrm{H}), 2.31$ д $\left(1 \mathrm{H}^{\mathrm{a}}\right), 2.43$ м $(2 \mathrm{H}), 2.52$ м $\left(1 \mathrm{H}^{\mathrm{b}}\right)$, 2.71 м $\left(1 \mathrm{H}^{\mathrm{b}}\right), 2.72 \mathrm{м}\left(1 \mathrm{H}^{\mathrm{b}}\right), 2.73$ м $(1 \mathrm{H}), 2.74$ м $\left(1 \mathrm{H}^{\mathrm{a}}\right)$, 3.23 м $(1 \mathrm{H}), 3.62$ т $(1 \mathrm{H}), 3.72$ с $(3 \mathrm{H}), 4.68$ д $\left(1 \mathrm{H}^{\mathrm{b}}\right)$, 4.71 д $\left(1 \mathrm{H}^{\mathrm{a}}\right), 5.22$ м $(2 \mathrm{H}), 5.26$ м $(1 \mathrm{H}), 5.59$ м $(1 \mathrm{H})$, 7.26 м (1Н). Спектр ЯМР ${ }^{13} \mathrm{C}, \delta$, м.д.: 14.11, 22.67, 27.44, 28.33, 29.13, 29.32, 29.47, 29.56, 31.89, 32.54, $33.35,33.95,34.0,38.22,38.3,39.7,52.18,57.67$, $74.29,119.5,124.03,134.02,135.54,135.59,135.67$, $135.93,136.03,139.23,139.36,139.70,140.23$, $141.57,141.64,141.88,141.93,142.12,142.19$, $142.24,142.43,142.61,142.67,142.72,143.07$, $143.12, \quad 144.40,144.47,144.52,144.76,145.02$, $145.11, \quad 145.22, \quad 145.35,145.47,145.57,145.91$, $145.98, \quad 146.11, \quad 146.11, \quad 146.25, \quad 146.28, \quad 146.34$, $146.38, \quad 147.26, \quad 147.36,147.64,148.12,148.25$, $150.70,151.01,152.71,156.99,164.11,176.62$, 179.54 .

\section{Результаты и их обсуждение}

В данной работе для функционализации ядра фуллерена $\mathrm{C}_{60}$ мы использовали реакцию [3+2]циклоприсоединения алленоатов на основе N- алкенилзамещеннного ангидрида янтарной кислоты. Аллены получают реакцией олефинирования кетенов фосфоранами, что в первую очередь связано с мягкими условиями проведения реакции [11-15]. Для этого хлорангидириды карбоновых кислот, которые при реакции с триэтиламином образуют кетены, далее in situ вовлекают в реакцию олефинирования с метил( трифенилфосфоранилиден)ацетатом (схема 1).

Структура полученных алленоатов доказана физико-химическими методами анализа. Для синтезированных алленоатов в спектре ЯМР ${ }^{13} \mathrm{C}$ информативными являются сигналы двух терминальных алленовых углеродных атомов в области $\delta_{\mathrm{c}} 88.17$ и 96.38 м.д., а также центральных четвертичных углеродных атомов, которые проявляются в области $\delta_{\mathrm{c}} 210.10-212.65$ м.д.

В результате реакции [3+2]-циклоприсоединения алленоатов к фуллереновому каркасу, как диполярофилу, образуются циклопентенофуллерены [5]. Процесс начинается с нуклеофильной атаки четвертичного углерода алленоата трифенилфосфином, что приводит к фосфорану. Далее последний, выступающий в роли 1,3-диполя, атакует фуллерен $\mathrm{C}_{60}$ по двойной связи с образованием пятичленного цикла; элиминирование катализатора $\mathrm{PPh}_{3}$ завершает получение целевого продукта (cxeма 2).

Схема 1<smiles>COC(=O)/C=C/CN1C(=O)CC(C(C)C)C1=O</smiles>

Схема 2

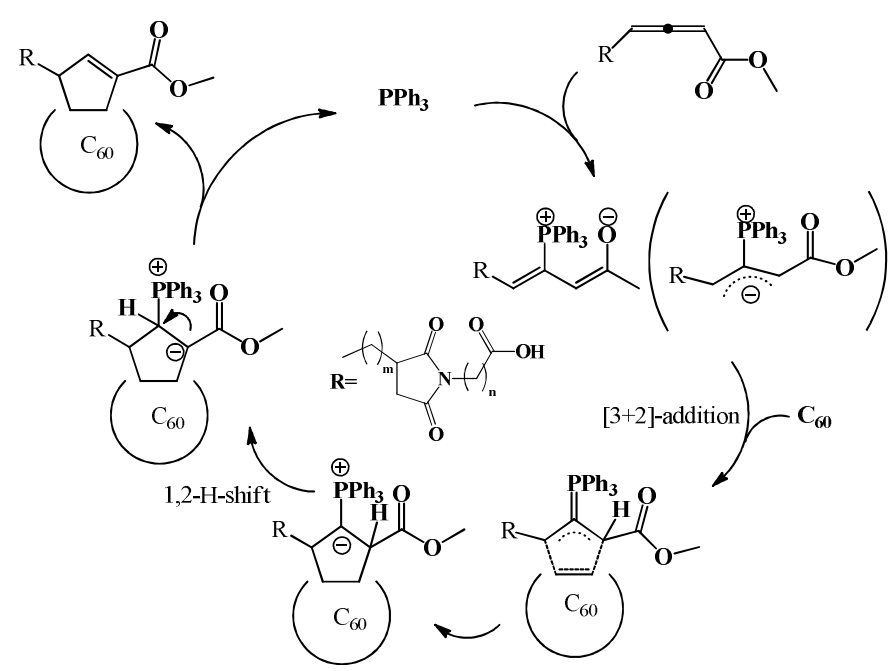




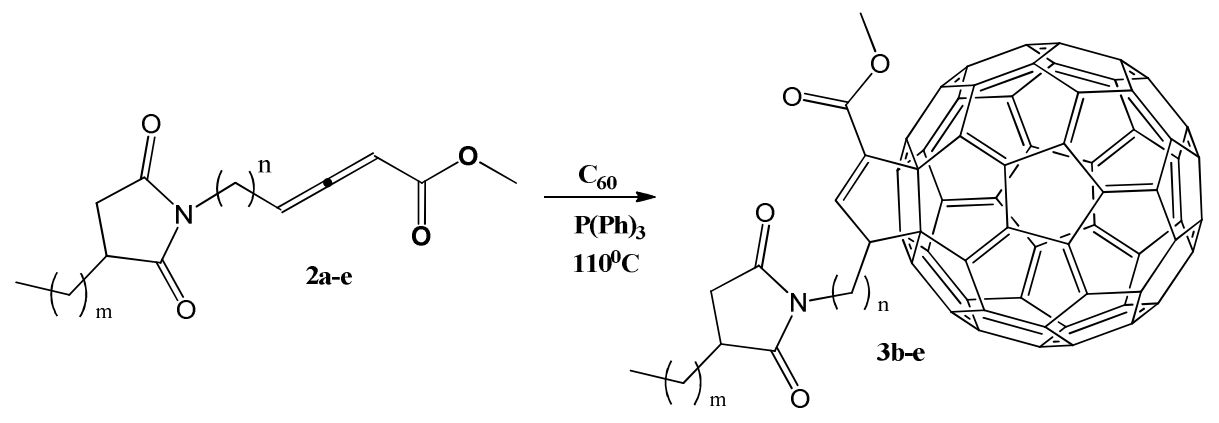

$$
\begin{aligned}
& \text { b: } n=2(60 \%), c: ~ n=3(52 \%), d: n=4(83 \%), e: ~ n=5(87 \%) \\
& \text { m=11 }
\end{aligned}
$$

Используя обозначенную методику, из алленоатов 2a-d синтезировали новые, хорошо растворимые в большинстве органических растворителей моноаддукты фуллерена 3a-d (схема 3).

Полученные аддукты растворяются в ТВИНЕ60 с образованием $\sim 10 \%$ растворов. Структуры выделенных соединений доказаны комплексом физико-химических методов.

\section{Выводы}

Таким образом, нами впервые синтезированы монофуллерены, содержащие остатки N-алкенилзамещеннного ангидрида янтарной кислоты путем реакции [3+2]-циклоприсоединения алленоатов к фуллереновому каркасу $\mathrm{C}_{60}$. Полученные конъюгаты фуллерена $\mathrm{C}_{60}$ показали хорошую растворимость как в органических растворителях, так и в ТВИНЕ-60.

Работа выполнена при финансовой поддержке Госзадания №AAAA-A20-120012090026-9 с использованием оборудования Центра коллективного пользования «Химия» Уфимского института химии УФИЦ РАН.

\section{ЛИТЕРАТУРА}

Monti D., Moretti L., Salvioli S., Straface E., Malorni W., Pellicciari R., Schettini G., Bisaglia M., Pincelli C., Fumelli C., Bonafe M., Franceschi C. $\mathrm{C}_{60}$ carboxyfullerene exerts a protective activity against oxidative stress-induced apoptosis in human peripheral blood mononuclear cells // Biochem. Biophys. Res. Commun. 2000. Vol. 277. Pp. 711-717.

2. Орлова М. А., Трофимова Т. П., Орлов А. П., Шаталов О. А., Свистунов А. А., Наполов Ю. К., Чехонин В. П. Фуллерены и оксидативный стресс // Онкогематология. 2012. T. 4. C. 11-15.

3. Каркищенко Н. Н. Нанобезопасность: новые подходы к оценке рисков и токсичности наноматериалов//Биомедицина. 2009. Т. 1. С. 5-27.

4. Tripkovic A., Todorovic-Markovic B., Kleut D. et al. Oxidative stress-mediated hemolytic activity of solvent ex- changeprepared fullerene $\left(\mathrm{C}_{60}\right)$ nanoparticles // Nanotechnol. 2010. Vol. 21. No 37. Pp. 75-102.

5. Hu Z., Guan W., Wang W. et al. Protective effects of a novel cystine C60 derivative on hydrogen peroxide-induced apoptosis in rat pheochromocytoma PC12 cells// Chemico-Biological Interactions. 2007. Vol.167. Pp.135-144.

6. Malikova R. N., Sakhautdinov I. M., Ishbaeva S. M., Yunusov M. S. Fullerene $\mathrm{C}_{60}$ Derivatives as Efficient Sensitizers of Oxidation under the Mild Conditions of Atmospheric Air // Russ. J. of Gen. Chem. 2017. Vol. 87. No 10. Pp. 2497-2499.

7. Sakhautdinov I. M., Malikova R. N., Akchurina O. V., Petrova S. F., Yunusov M. S. Synthesis of new lipophilic rosinbasedmethanofullerenes from bromo- andchloromethylketones N-substitutedproteinogenic amino acids // Lett. Org. Chem. 2017. Vol. 14. Pp. 575-584.

8. Сахаутдинов И. М., Маликова Р. Н.,, Нугуманов Т. Р, Биглова Ю. Н., Атангулов А. Б., Юнусов М. С. Циклоприсоединение хлорметилкетонов n-малеопимаримидзамещенных аминокислот к фуллерену $\mathrm{C}_{60}$ по Бингелю // Химия природных соединений. 2018. №3. С. 408-412.

9. Bosi S., Da Ros T., Castellano S., Banfi E., Prato M. Antimycobacterial activity of ionic fullerene derivatives // Bioorg. Med. Chem. Lett. 2000. Vol. 10. Pp. 1043-1045.

10. Lin A. M., Fang S.-F., Lin S.-Z., Chou C.-K., Luh T.-Y., Ho L.-T. Local carboxyfullerene protects cortical infarction in rat brain // Neurosci. Res. 2002. Vol. 43. Pp. 317-321.

11. Silveira C., Boeck P. and Braga A. A convenient synthesis of 4-phenylchalcogeno allenic esters from $\alpha$-(phenylchalcogeno)acid chlorides // Tetrahedron Lett. 2000. Vol. 41. Pp. $1867-1869$.

12. Li C., Zhu B., Ye L.-Y., Jing Q., Sun X.-L., Tanga Y., Shen Q. Olefination of ketenes for the enantioselective synthesis of allenes via an ylide route// Tetrahedron. 2007. Vol. 63. Pp. 8046-8053.

13. Sakhautdinov I. M., Gumerov A. M., Gibadullina G. G., Zakiryanova O. V., Yunusov M. S. Synthesis of a 2,3-Dienoate Based on Methyl Maleopimarate // Chem. Nat. Compd. 2015. Vol. 2. Pp. 383-384.

14. Marco-Martnez J., Marcos V., Reboredo S., Filippone S., Mart N., Stereodivergent-at-Metal Synthesis of [60]Fullerene Hybrids // Angew.Chem. Int. Ed. 2017. Vol. 56. Pp. 1-5.

15. Sakhautdinov I. M., Gumerov A. M., Batyrshin I. R., Fatykhov A. A., Yunusov M. S., Suponitsky K. Yu Synthesis of Pyrazoles Based on Functionalized Allenoates // Heterocycles. 2014. Vol. 89. Pp.641-651. 
DOI: $10.33184 /$ bulletin-bsu-2021.3.20

\title{
SYNTHESIS OF NEW LIPOPHILIC DERIVATIVES OF FULLERENE C60
}

\author{
(C) I. M. Sakhautdinov ${ }^{1 *}$, A. F. Islamova ${ }^{1,2}$, T. A. Mananov ${ }^{3}$, \\ A. M. Gymerov ${ }^{2,3}$ \\ ${ }^{1}$ Ufa Institute of Chemistry, Ufa Federal Research Center of RAS \\ 71 Oktyabrya Avenue, 450054 Ufa, Republic of Bashkortostan, Russia. \\ ${ }^{2}$ Republic Engineering Lyceum \\ 74 Kol'tsevaya Street, 450032 Ufa, Republic of Bashkortostan, Russia. \\ ${ }^{3}$ Ufa State Petroleum Technological University \\ 1 Kosmonavtov Street, 450064 Ufa, Republic of Bashkortostan, Russia. \\ Phone: +7 (347) 2355560 . \\ *Email:ioh039@mail.ru
}

Fullerene $\mathrm{C}_{60}$ derivatives have an unusually high ability to scavenge free radicals, the so-called effect of "radical sponges", which can be used to create antioxidants. Experiments on animals show that fullerene compounds markedly increase their resistance to oxidative stress. For the functionalization of the fullerene $\mathrm{C}_{60}$ nucleus, the authors of the work used $[3+2]$-cycloaddition allenoates based on $\mathrm{N}$-alkenyl-substituted succinic acid anhydride. Allenes were obtained by the reaction of olefination of ketenes with phosphoranes, which is primarily associated with the mild conditions of the reaction. For this purpose, carboxylic acid chlorides, which form ketenes upon reaction with triethylamine, were in situ involved in the olefination reaction with methyl (triphenylphosphoranylidene) acetate. It is known that as a result of organocatalysis [3+2]-cycloaddition of allenoates to the fullerene framework, like a dipolarophile, cyclopentenofullerenes are formed. The process begins with a nucleophilic attack on the quaternary carbon of the allenoate with triphenylphosphine, resulting in phosphorane. Further, the latter, acting as a 1,3-dipole, attacks the $\mathrm{C}_{60}$ fullerene at a double bond, and a five-membered cycle appears. Elimination of the PPh3 catalyst completes the production of the target product. Using the indicated technique, new fullerene monoadducts, readily soluble in most organic solvents, were synthesized from allenoates. Thus, the authors have synthesized for the first time monofullerenes containing residues of $\mathrm{N}$-alkenylsubstituted succinic anhydride by [3+2]-cycloaddition of allenoates to the $\mathrm{C}_{60}$ fullerene framework. The obtained $\mathrm{C}_{60}$ fullerene conjugates dissolve well not only in organic solvents, but also in TWIN-60.

Keywords: fullerenes, succinic acid anhydride, allenoates, cyclopentenofullerenes.

Published in Russian. Do not hesitate to contact us at bulletin_bsu@mail.ru if you need translation of the article.

\section{REFERENCES}

1. Monti D., Moretti L., Salvioli S., Straface E., Malorni W., Pellicciari R., Schettini G., Bisaglia M., Pincelli C., Fumel-li C., Bonafe M., Franceschi C. Biochem. Biophys. Res. Commun. 2000. Vol. 277. Pp. 711-717.

2. Orlova M. A., Trofimova T. P., Orlov A. P., Shatalov O. A., Svistunov A. A., Napolov Yu. K., Chekhonin V. P. Onkogematologiya. 2012. Vol. 4. Pp. 11-15.

3. Karkishchenko N. N.Biomeditsina. 2009. Vol. 1. Pp. 5-27.

4. Tripkovic A. Nanotechnol. 2010. Vol. 21. No 37. Pp. 75-102.

5. Hu Z., Guan W., Wang W. et al. Chemico-Biological Interactions. 2007. Vol.167. Pp.135-144.

6. Malikova R. N., Sakhautdinov I. M., Ishbaeva S. M., Yunusov M. S. Russ. J. of Gen. Chem. 2017. Vol. 87. No 10. Pp. 2497-2499.

7. Sakhautdinov I. M., Malikova R. N., Akchurina O. V., Petrova S. F., Yunusov M. S. Lett. Org. Chem. 2017. Vol. 14. Pp. 575-584.

8. Sakhautdinov I. M., Malikova R. N., Nugumanov T. R, Biglova Yu. N., Atangulov A. B., Yunucov M. S. Khimiya prirodnykh soedinenii. 2018. No. 3. Pp. 408-412.

9. Bosi S., Da Ros T., Castellano S., Banfi E., Prato M. Bioorg. Med. Chem. Lett. 2000. Vol. 10. Pp. 1043-1045.

10. Lin A. M., Fang S.-F., Lin S.-Z., Chou C.-K., Luh T.-Y., Ho L.-T. Neurosci. Res. 2002. Vol. 43. Pp. $317-321$.

11. Silveira C., Boeck P. and Braga A. Tetrahedron Lett. 2000. Vol. 41. Pp. 1867-1869.

12. Li C., Zhu B., Ye L.-Y., Jing Q., Sun X.-L., Tanga Y., Shen Q. Tetrahedron. 2007. Vol. 63. Pp. 8046-8053.

13. Sakhautdinov I. M., Gumerov A. M., Gibadullina G. G., Zakiryanova O. V., Yunusov M. S. Chem. Nat. Compd. 2015. Vol. 2. Pp. 383-384.

14. Marco-Martnez J., Marcos V., Reboredo S., Filippone S., Mart N. Angew.Chem. Int. Ed. 2017. Vol. 56. Pp. 1-5.

15. Sakhautdinov I. M., Gumerov A. M., Batyrshin I. R., Fatykhov A. A., Yunusov M. S., Suponitsky K. Heterocycles. 2014. Vol. 89. Pp.641-651. 